\section{Entre vacinas, doenças e resistências: os impactos de uma epidemia de varíola em Porto Alegre no século XIX}

\section{Between vaccines, diseases, and resistances: the impacts of a smallpox epidemic in nineteenth-century Porto Alegre}

\author{
Fábio Kühn ${ }^{i}$ \\ i Professor, Departamento de História/ \\ Universidade Federal do Rio Grande do Sul. \\ Porto Alegre - RS - Brasil \\ orcid.org/0000-0001-7552-4288 \\ fabio.kuhn@ufrgs.br \\ Jaqueline Hasan Brizola ${ }^{i i}$ \\ ii Mestre pelo Programa de Pós-graduação em História/ \\ Universidade Federal do Rio Grande do Sul. \\ Porto Alegre - RS - Brasil \\ orcid.org/0000-0003-4339-994X \\ brizajaque@gmail.com
}

Recebido em 10 out. 2017.

Aprovado em 28 maio 2018.
KÜHN, Fábio; BRIZOLA, Jaqueline Hasan. Entre vacinas, doenças e resistências: os impactos de uma epidemia de varíola em Porto Alegre no século XIX. História, Ciências, Saúde - Manguinhos, Rio de Janeiro, v.26, n.2, abr.-jun. 2019, p.537-554.

\section{Resumo}

Uma epidemia de varíola que vitimou fatalmente $1 \%$ da população de Porto Alegre em 1874 é o tema deste artigo. Com base em ampla pesquisa documental e no cruzamento de informações produzidas por ocasião da morte dos indivíduos atingidos durante o evento, buscamos problematizar as razões pelas quais a varíola apresentouse em formato epidêmico na cidade. De posse dos mapas de vacinados nos anos anteriores à eclosão da epidemia, pudemos constatar a baixa adesão da população de Porto Alegre ao preventivo, cujo benefício poderia ser ignorado pelos distintos grupos sociais que teciam relações dentro da cidade. Com a chegada de soldados doentes, oriundos de outras localidades, a moléstia se espalhou rapidamente pela cidade, causando a morte de centenas de pessoas.

Palavras-chave: epidemia; varíola; século XIX; Porto Alegre.

\section{Abstract}

This article examines a smallpox epidemic which killed $1 \%$ of the population of Porto Alegre in 1874. Through extensive documentary research and comparison with data from those who died, we problematize why smallpox manifested as an epidemic in the city. Maps showing vaccination in the years preceding the outbreak reveal that only low levels of the population of Porto Alegre participated in prevention efforts, and the benefits of these efforts were ignored by the different social groups which were interconnected within the city. As sick soldiers arrived from other places, the disease spread rapidly through the city and caused the death of hundreds of people.

Keywords: epidemic; smallpox; nineteenth century; Porto Alegre. 
$\mathrm{D}$ ois de junho de 1874, o menino de 4 anos Norberto, filho de Maurícia Maria da Conceição, faleceu em Porto Alegre. Seu flagelo: varíola; a mãe Maurícia, mulher de 22 anos, tivera o mesmo destino do filho. Ambos permaneceram por algum tempo no lazareto de varíola localizado no caminho dos Moinhos de Vento, mas não resistiram à terrível moléstia. Foram enterrados no dia seguinte ao falecimento, no cemitério da Santa Casa, em um terreno destinado aos pobres, escravos e desvalidos: o Campo Santo. ${ }^{1}$

Maurícia e Norberto eram originários de uma província onde os óbitos por varíola haviam diminuído bastante nos 28 anos anteriores a sua morte. A vacinação contra a doença era praticada em muitas localidades no Rio Grande de São Pedro, segundo os relatórios de presidentes da província, que traziam os mapas de vacinados anexos aos seus balancetes anuais. Contudo, em fins de 1873 e princípios de 1874, a moléstia, que deveria estar sendo combatida com intensidade na província sulina, continuava causando estragos, e, dessa vez, os números de contágios e óbitos superavam os limites aceitáveis para uma doença endêmica, como fora até então. ${ }^{2}$

Neste artigo discutiremos os impactos sociais causados pela varíola em Porto Alegre, com destaque para 1874, por ocasião da epidemia que assolou a cidade. Interessa-nos demonstrar como e por que, após tantos anos de tentativas de imunização, os sujeitos ainda se viam desprotegidos do flagelo das bexigas. A eclosão da epidemia teria alguma relação com a falta da vacina ou com a dificuldade de sua aplicabilidade? Quem foram os sujeitos atingidos? E, ainda, o que o perfil social dos indivíduos que faleceram em função da doença pode nos dizer sobre as causas imediatas de eclosão da epidemia?

De posse de informações oriundas dos livros de óbitos da Cúria Metropolitana de Porto Alegre e da Santa Casa de Misericórdia, pudemos conhecer o universo da morbidade causada pela varíola entre 1846 e 1874 e, assim, estabelecer uma noção mais aproximada do impacto social que a doença tivera na cidade. ${ }^{3}$ Dados como nome, idade, origem, sexo ou situação de enterramento permitem aos pesquisadores acumular uma série de informações úteis à compreensão da trama social que investigam no passado. Mas o que efetivamente deve ser considerado uma série? Qual a relação da história serial com a metodologia quantitativa? E de que modo nos aproximamos desses conceitos para construir nossa abordagem? Em um primeiro plano, torna-se fundamental estabelecer uma distinção entre a abordagem serial e a metodologia quantitativa, já que ambas, segundo (Barros, 2012) são normalmente interpretadas como duas faces da mesma moeda. Para o historiador, a "série" pode ser entendida como parte constituinte de uma grande cadeia de fontes do mesmo tipo, "onde os dados devem ser comparáveis, capazes de serem apreendidos no interior de uma dada continuidade, tornando possível uma abordagem de conjunto através de aportes metodológicos, como a quantificação" (p.205).

A abordagem serial, portanto, não é necessariamente quantitativa. Isso porque o que se busca na série é a recorrência, e não os números propriamente ditos. Desse modo, uma análise qualitativa também pode ser identificada dentro de uma série, a partir do momento que um conjunto de documentos contendo discursos produzidos em esferas diferenciadas são aproximados para compor um cenário dificilmente compreensível, não fosse a capacidade do(a) historiador(a) em identificar recorrências em suas fontes. Nesse sentido, "pode-se compreender como uma 'série' tanto os fatos repetitivos que permitem 
ser avaliados comparativamente como uma determinada documentação homogênea" (Barros, 2012, p.205).

Os dados obtidos a partir dos registros de óbitos e de entradas de pacientes da Santa Casa, analisados em conjunto com outras fontes de ordem qualitativa, como jornais de época ou documentos da administração provincial, ajudam-nos a esclarecer alguns vieses do comportamento social dos indivíduos do passado em relação ao adoecimento.

Ao investigar as elaborações possíveis diante da doença ou da morte numa dada comunidade, deparamo-nos com interpretações divergentes quanto a causas, tratamentos e/ou métodos de prevenção. Obedecendo aos costumes advindos de tradições familiares ou religiosas, por exemplo, os indivíduos constroem seus significados de acordo com o universo de experiências compartilhadas ao longo de sucessivas gerações na hora de tratar seus males.

A importância dos costumes na elaboração de sujeitos preocupados em preservar a sua própria cultura foi amplamente discutida pelo historiador britânico Edward Thompson (1998, p.22), para quem a cultura costumeira não está sujeita, em seu funcionamento cotidiano, ao domínio ideológico dos governantes, ao contrário, respeita os "ritos, modos simbólicos, os atributos culturais da hegemonia, a transmissão do costume de geração para geração".

Nesse sentido, as reflexões teóricas expressas pelo autor nos auxiliam a problematizar as visões da massa anônima na história, e lhe conferem, além do mais, status e importância real no estudo dos fenômenos do passado. Sob a influência da história social, entendemos que os homens e mulheres que compartilharam os dilemas da epidemia de varíola em 1874, mas também aqueles e aquelas que conviveram com a doença ao longo do século XIX, rejeitaram a vacinação estatal não apenas por medo e ignorância das formas de contágio, mas também e sobretudo para preservar sua própria cultura, seus métodos de tratamento ou seus rituais na hora da morte. ${ }^{4}$

Alguns trabalhos importantes sobre a história da saúde na província, ao longo do século XIX, chamam atenção para os hábitos da população no que se refere à preservação de seus corpos. Nikelen Witter (2007), que estudou a grande epidemia de cólera em 1855, afirmou que os agentes do governo imperial não foram capazes de oferecer respostas eficientes no quadro epidêmico e que não eram incomuns os embates entre população, governo local e provincial acerca de como tratar ou prevenir a doença. Beatriz Weber (1992) e Wladimir Ávila (2010), que estudaram as posturas municipais em Porto Alegre, observaram a tentativa, pelos poderosos locais, de estabelecer regras sanitárias capazes de minimizar o impacto das doenças, o que implicava desconstituir os hábitos das populações menos favorecidas, considerados perniciosos à saúde.

Claudia Tomaschewski (2014) e Daniel Oliveira (2012) também se inserem entre os pesquisadores que contribuíram recentemente para ampliar os debates acerca da história da saúde e das doenças no Rio Grande do Sul. Tendo como referência a documentação da Santa Casa de Misericórdia de Porto Alegre, no caso de Oliveira, e de Pelotas, no de Tomaschewski, podemos entender mais e melhor os diferentes papéis desempenhados por essas instituições no século XIX, no rol das opções de tratamento e cura experimentados pelos habitantes da província. 
Bem menos conhecidos, entretanto, eram os impactos das famosas bexigas, ${ }^{5}$ que estiveram presentes no território brasileiro durante todo o período colonial, conforme Sá (2008), e imperial, segundo Chalhoub (1996) e Fernandes (2003). Essa abordagem busca contribuir com o entendimento dos processos que levaram à eclosão da varíola no século XIX em Porto Alegre, à luz das possibilidades existentes e das opções disponíveis aos sujeitos que teciam relações dentro da cidade.

\section{A epidemia de varíola em Porto Alegre}

Após o levantamento dos óbitos ocorridos em 1874, sabemos que, pelo menos, 1\% da população total da cidade faleceu em função das bexigas. Se somarmos o número de óbitos com o número de contágios, podemos garantir que 1,5\% da população de Porto Alegre, segundo os registros oficiais, estiveram em contato com a doença em 1873 e $1874 .^{6}$ Esse número pode parecer modesto se pensarmos na epidemia de cólera, que só em 1855 ceifou a vida de $10 \%$ da população da cidade, mas torna-se bastante expressivo quando estabelecemos outras comparações. ${ }^{7}$

Segundo Rodrigues (1999), a epidemia de febre amarela no Rio de Janeiro, em 1849 e 1850, provocou a morte de 4.162 pessoas, pelos dados oficiais. Cabe lembrar que a população carioca à época esteve estimada em 166 mil pessoas aproximadamente, ${ }^{8}$ o que nos leva a um percentual de 2,5\% de óbitos decorrentes da doença entre a população da Corte. Sabemos que os impactos causados pela febre amarela foram profundos; muitos autores atribuem algumas das mudanças verificadas no campo da saúde e higiene na década de 1850 à eclosão daquela epidemia. ${ }^{9}$ Imaginemos, então, o impacto social que teve a varíola, no período mencionado, quando causou em Porto Alegre, em 1874, proporcionalmente quase a metade do número de óbitos que a febre amarela levou ao Rio de Janeiro em 1850.

No caso da varíola, a vacina deveria constituir-se em um importante preventivo para seu controle, não apenas na capital sulina, mas também em todo o Império do Brasil (Fernandes, 2010). Em 1874, a vacina estava prestes a completar 100 anos de existência, mas a doença continuava causando estragos terríveis na população porto-alegrense do século XIX, em função de sua ampla resistência ao preventivo. Ameaçados pelo contágio, os grupos que conviviam na cidade de Porto Alegre foram capazes de elaborar métodos próprios no combate à enfermidade. De posse de alguns relatórios de presidentes da província, pudemos constatar a preocupação, por parte de mandatários sulistas, com a chamada variolização, que, segundo Manoel Antônio Galvão, em 1847, era prática recorrente no interior da província, sendo, em alguns casos, mais aceita que a vacina regular (Relatório de Manoel..., 1847). ${ }^{10}$

Embora alguns agentes governamentais estivessem somando esforços para implementar a vacina ou medidas de profilaxia, a população apresentou uma baixa adesão à vacinação, como podemos visualizar na Tabela 1. 
Tabela 1: Mapa de vacinados (1851-1871)

\begin{tabular}{c|c|c|c|c|c|c|c|c}
\hline Ano & Homens & Mulheres & Crianças & Livres & Escravos & s/efeito & s/observação & Total \\
\hline 1851 & - & - & 288 & 301 & 167 & 102 & 170 & 468 \\
$1852-1853$ & 208 & 188 & & 276 & 120 & 48 & 57 & 396 \\
$1854-1855$ & 421 & 318 & & 516 & 223 & 50 & 88 & 739 \\
$1858-1859$ & 360 & 288 & 304 & 301 & 167 & 102 & 170 & 648 \\
$1861-1862$ & 392 & - & 498 & 198 & 182 & 109 & 696 \\
1871 & - & - & 393 & 149 & - & - & 542 \\
Total & 1.381 & $\mathbf{1 . 0 9 8}$ & & $\mathbf{2 . 2 8 5}$ & $\mathbf{1 . 0 2 4}$ & $\mathbf{4 9 0}$ & $\mathbf{5 9 4}$ & $\mathbf{3 . 4 8 9}$ \\
\hline
\end{tabular}

Fonte: Relatórios... $(1856,1871)$.

Entre 1851 e 1871, encontramos registros oficiais de 3.489 pessoas em Porto Alegre que se submeteram à vacinação, entre homens, mulheres e crianças. Desses, 2.285 eram sujeitos livres e 1.024, escravos. Mesmo que os dados possam estar incompletos - o que supomos pela falta de registro de vacinação em crianças para os anos posteriores a 1851 -, os números expostos são representativos para a análise da funcionalidade da vacinação e também da resistência das pessoas em contribuir para o sucesso do preventivo, pois a indicação "não foram observados", que aparece na tabela como "s/observação", significa provavelmente que os vacinados não voltaram após os oito dias para fornecer o pus necessário a novas inoculações. ${ }^{11}$

Analisando os dados da Tabela 1, podemos perceber que era baixo o percentual de sujeitos vacinados. Embora os livres apareçam em maior quantidade, segundo os números absolutos, o percentual de imunização foi maior entre os cativos. Paulo Moreira nos apresentou a estatística da população de Porto Alegre para 1856, 1858, 1860 e 1872. Para o melhor entendimento do percentual de vacinação em relação à população total da cidade, utilizamos na Tabela 2 os dados apresentados pelo autor. ${ }^{12}$

Tabela 2: População vacinada versus população geral (1858-1871)

\begin{tabular}{c|c|c|c|c|c|c|c|c}
\hline Ano & $\begin{array}{c}\text { Livres } \\
\text { vacinados }\end{array}$ & $\begin{array}{c}\text { População } \\
\text { livre de } \\
\text { Porto } \\
\text { Alegre }\end{array}$ & $\begin{array}{c}\text { Livres } \\
\text { vacinados } \\
\text { em relação } \\
\text { à pop. livre } \\
\text { (\%) }\end{array}$ & $\begin{array}{c}\text { Escravos } \\
\text { vacinados }\end{array}$ & $\begin{array}{c}\text { População } \\
\text { escrava } \\
\text { de Porto } \\
\text { Alegre }\end{array}$ & $\begin{array}{c}\text { Escravos } \\
\text { vacinados } \\
\text { em relação } \\
\text { à pop. } \\
\text { escrava (\%) }\end{array}$ & $\begin{array}{c}\text { População } \\
\text { total Porto } \\
\text { Alegre }\end{array}$ & $\begin{array}{c}\text { Total de } \\
\text { vacinados } \\
\text { (\%) }\end{array}$ \\
\hline $1854-1855$ & 513 & 12.080 & 4,24 & 323 & 5.146 & 6,27 & 17.226 & 4,85 \\
$1858-1859$ & 301 & 12.820 & 2,34 & 167 & 5.070 & 3,29 & 18.538 & 2,52 \\
$1861-1862$ & 498 & 21.167 & 2,35 & 198 & 8.658 & 2,28 & 31.339 & 2,22 \\
1871 & 393 & 35.843 & 1,96 & 149 & 8.155 & 1,82 & 43.998 & 1,23 \\
\hline
\end{tabular}

Fonte: Relatórios... (1856, 1871); Moreira (2003, p.29). 
Como se pode observar, o número de indivíduos vacinados oscilou entre 1 e $4 \%$ da população total da cidade entre 1854 e 1871. Uma adesão inexpressiva, considerando a magnitude do problema. Conforme a população aumentava, o número de vacinados decrescia, o que deve ter contribuído para a eclosão da epidemia em 1874. Concordando com Chalhoub (1996, p.113), que constatou o mesmo comportamento de não adesão da população carioca à vacina regular, certamente era difícil convencer as pessoas a aceitar a lanceta, quando a varíola não se manifestava epidemicamente.

Como justificativa para o índice baixo de vacinados no período, apontava o presidente da província em 1847 as seguintes questões:

A vacina não tem produzido nesta província os resultados que na maior parte das cidades marítimas do Império se tem alcançado deste preservativo, ou concorra para esta falta o descuido natural dos que mais interessados deviam ser no seu emprego ou a crença de não garantir Ela o ataque da bexiga epidêmica os já vacinados (Relatório de Manoel..., 1847, s.p.).

A fala de Manoel Antônio Galvão demonstra as dificuldades inerentes à propagação da vacina. O presidente apontava o "descuido natural" das pessoas como primeiro item de um conjunto de empecilhos ao sucesso do preventivo. A crença de que a vacina não garantia a imunização por completo baseava-se, certamente, na experiência de outros sujeitos que, uma vez vacinados, contraíram posteriormente a doença.

De qualquer maneira, a vacina não era uma prática regular em Porto Alegre, e vários motivos concorriam para isso. Em primeiro plano, há que ressaltar que não havia um consenso sobre as medidas que deveriam ser tomadas em relação à "saúde pública". Algumas interpretações com base no pensamento de Michel Foucault (1996) sobre a saúde pública problematizaram a constituição dos serviços de saúde no Brasil dentro de um contexto de relações que emergem na época moderna, daí o surgimento de posturas que cumprissem o papel de organizar os métodos de combate às doenças e que também elegessem os lugares onde deveriam transitar os doentes (Machado, 1979).

Para entendermos as ações protagonizadas pelos diferentes sujeitos que teciam relações dentro da cidade de Porto Alegre no século XIX, no que concerne à manutenção de sua saúde, entretanto, precisamos relativizar a ideia de que os agentes do governo imperial detinham poder inconteste e absoluto sobre os corpos dos indivíduos ou a de que aquela sociedade patriarcal e escravocrata estivesse pautada pela lógica da medicalização da sociedade. ${ }^{13}$

A abordagem acerca da instituição do preventivo contra a varíola em Porto Alegre se pauta a partir do entendimento de uma série de mudanças ocorridas no Brasil no campo da saúde no período referido. A formação de um campo político orientado a pensar a saúde pública de forma centralizada ocorrerá paralelamente às tentativas de imunização. Há que ressaltar, entretanto, que não havia consenso nem mesmo entre os médicos ou práticos da saúde à época quanto ao benefício da vacina ou as formas adequadas de tratamentos; o que se pode observar, já em 1846, é a tentativa de incorporação pela esfera pública de temas anteriormente regidos pela esfera privada, como era o caso do combate à varíola ou de sua prevenção. ${ }^{14}$ 
Nesse sentido, como demonstrou Telarolli Jr. (1996), as práticas de saúde no Império estavam mais centradas em acabar com as grandes epidemias do que em organizar os hospitais ou os socorros públicos, mas diversas mudanças associadas à formação do Estado imperial, principalmente após o Segundo Reinado, concorreram para a implantação no Brasil de uma prática médica como ação estatal. As decisões em termos de higienismo, urbanismo, educação e prevenção eram tomadas associadas cada vez mais à temática da saúde.

Não por acaso, a expressão "saúde pública" passa a ser utilizada de forma recorrente pelas autoridades, tanto do Império quanto da província. Mesmo que as noções do "público" naquela sociedade escravocrata e patriarcal diferissem em muito do que hoje concebemos ao pensar no termo, é inegável que havia uma preocupação em centralizar as atividades, não no sentido de promover melhores condições de vida e saúde para a população, mas sim na intenção de combater males antigos, como era o caso das epidemias, diminuindo suas ocorrências fatais à luz das novas descobertas no campo da ciência e da medicina. ${ }^{15}$

As elaborações aceitas no combate a varíola, contudo, poderiam ser variadas. $\mathrm{O}$ método de inoculação coordenado por agentes do governo gerou medo e desconfiança entre a população que, além do mais, não estava informada dos potenciais benefícios do preventivo. ${ }^{16}$ A prática da "variolização", pensada por populares, foi motivo de alerta para alguns mandatários sulistas, mas, provavelmente, mediante uma situação de risco, as pessoas seguiam autorizando métodos de combate à doença compartilhados no interior de sua própria comunidade.

Charles Rosenberg (1992) nos lembra que os impactos e as representações da doença se transformam de acordo com as características de cada sociedade, em cada período, o que implica uma alteração no comportamento das pessoas e em suas experiências. Não deveríamos, então, falar em uma doença apenas, porque nesse conceito caberiam inúmeras representações e distintas sensações. Da mesma maneira que a experiência no sentir a doença é diversificada para aqueles e aquelas que a viveram, os modos pelos quais os indivíduos combatem seus males no passado não obedecem a uma só regra, podem apresentar as mais distintas elaborações.

\section{Conhecendo os sofredores}

Em 1874, a cidade de Porto Alegre possuía uma população em franco crescimento. O número de habitantes chegara à marca de quarenta mil pessoas, e o espaço urbano expandia-se para além dos limites anteriormente delimitados pelos portões da Santa Casa de Misericórdia. ${ }^{17} \mathrm{~A}$ capital sulina há algum tempo não protagonizava uma epidemia de bexigas. A varíola, entretanto, era velha conhecida da população da cidade, como se pode apreender pela leitura do Gráfico 1: 
Gráfico 1: Óbitos por varíola: população livre e escrava (1846-1874)

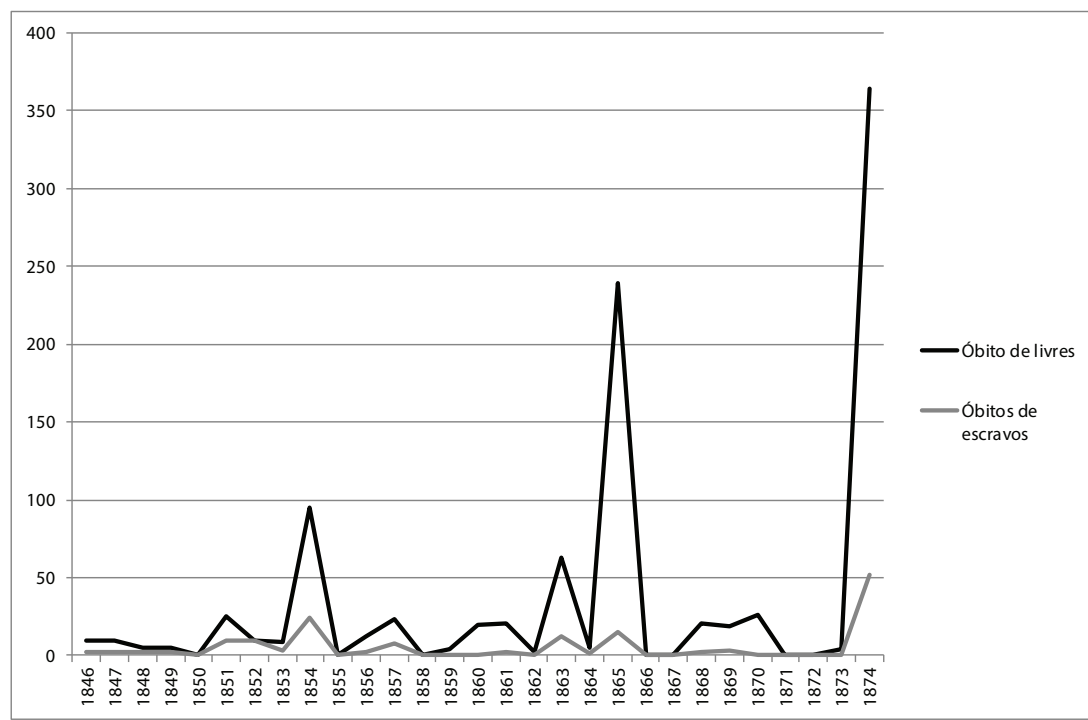

Fonte: CHC Santa Casa (2007); Livro de óbitos... (1850-1855, 1856-1866, 1867-1874); Livro de óbitos de escravos... (1846-1850).

Durante o período marcado pela introdução da vacina regular, em 1846, e a epidemia de 1874, o número de óbitos por bexigas foi maior entre a população livre e se manteve estável entre os escravos. Pela leitura do gráfico, notamos que a doença, endêmica na cidade, alcançou surtos consideráveis em 1854, 1863 e $1865 .{ }^{18}$ Com o advento da Guerra do Paraguai e o maior fluxo de soldados circulando na província, a varíola não tardou a se manifestar. ${ }^{19}$ Contabilizamos 253 óbitos decorrentes da doença em Porto Alegre no ano da eclosão do conflito. Diante de um número tão expressivo, poderíamos considerar a existência de dois surtos epidêmicos na capital sulina, um em 1865, outro em 1874.

A análise dos registros de óbitos daqueles que padeceram em 1865, contudo, mostrou que a maioria dos atingidos foi de soldados do Corpo de Voluntários da Pátria ou da Guarda Nacional, fato que não exclui, mas minimiza o impacto entre a população da cidade. ${ }^{20}$ Informando o estado de salubridade da província em 1866, em seu longo relatório à Assembleia Provincial, o então vice-presidente Antonio Augusto Pereira da Cunha foi sucinto ao analisar o surto epidêmico ocorrido no ano anterior. Segundo ele:

Além das bexigas e febres tifoides, nenhuma outra epidemia tem grassado na província. 'Aquelas fizeram não pequeno estrago, mormente entre os praças do Corpo dos Voluntários da Pátria', devido isso talvez a mudança de clima e alimentos, e falta de asseio e cômodos nos navios que o transportava (Relatório de Antonio..., 1866, s.p.; destaques nossos).

A morte de 239 pessoas livres e 15 escravos, ao que parece, não comoveu nem tampouco abalou as estruturas da cidade, talvez porque a maioria dos atingidos fosse de homens, soldados, originários de outras localidades. Não encontramos menções sobre o acontecido na imprensa da capital nem qualquer relato mais detalhado na documentação provincial. Pereira da Cunha limitou-se a comentar o evento, apontando os principais atingidos. ${ }^{21}$ 
Maria Tereza Dourado (2011) apontou a varíola como a doença que mais mortes causou entre as muitas que assolaram os combatentes durante a campanha do Paraguai. Em algumas cidades como Cuiabá, no Mato Grosso, a moléstia espalhou-se para os civis com extrema facilidade, tendo causado milhares de óbitos entre a população da capital mato-grossense em 1867.

Não verificamos esse cenário em Porto Alegre. A epidemia de 1865, ao que parece, ficou circunscrita às forças militares, ocasionando o óbito de alguns poucos civis. Em nenhum momento, no período estudado, houve mortandade semelhante àquela verificada no Mato Grosso em 1867, por ocasião da guerra contra o Paraguai. De qualquer maneira, as curvas variantes do Gráfico 1 são representativas para análise da varíola enquanto doença endêmica na capital sulina durante todo o século XIX.

Assim, nossa opção em analisar mais detalhadamente a epidemia de 1874 se explica por duas razões fundamentais. Primeiro, porque atingiu maior número de pessoas, segundo, por ter infectado civis majoritariamente, sujeitos que residiam na cidade de Porto Alegre e que não exerciam atividade militar. Entre os falecidos na condição de livres em 1865, há um percentual baixo de homens e mulheres oriundos da capital ou da província, 23\% apenas, contra 81\% em 1874 .

Os livres, entretanto, estiveram mais vulneráveis à varíola tanto no quadro endêmico quanto no epidêmico. Como veremos a partir de agora, a população livre fora duramente castigada durante a epidemia de 1874. Em Porto Alegre, ocorreram 364 óbitos naquele ano. Evidentemente, em 12 meses de contágios e mortes, houve um período mais crítico, que, segundo a análise que propomos, corresponde aos meses de março a agosto de 1874. Mas, se existiu uma desproporção entre os óbitos de livres e escravos, o que poderíamos dizer a respeito do sexo ou faixa etária desses indivíduos? Destacando alguns detalhes do registro de enterramento daqueles que morreram no período em questão, veremos que o perfil social dos atingidos poderia não obedecer a uma só regra, como se pode apreender na leitura da Tabela 3:

Tabela 3: Obituário da população de Porto Alegre por varíola segundo a faixa etária, epidemia de 1874

\begin{tabular}{|c|c|c|c|c|c|c|}
\hline Idades & $\begin{array}{c}\text { Livres } \\
\text { (n. absolutos) }\end{array}$ & (\%) & $\begin{array}{c}\text { Escravos } \\
\text { (n. absolutos) }\end{array}$ & (\%) & $\begin{array}{c}\text { Total } \\
\text { (n. absolutos) }\end{array}$ & Total (\%) \\
\hline 0 a 5 & 93 & 25,54 & 1 & 0,27 & 94 & 26,11 \\
\hline 6 a 11 & 30 & 8,20 & 2 & 0,54 & 32 & 8,74 \\
\hline 12 a 17 & 28 & 7,60 & 4 & 1,09 & 32 & 8,69 \\
\hline 18 a 22 & 57 & 15,60 & 10 & 2,74 & 67 & 18,34 \\
\hline 23 a 27 & 33 & 9,00 & 11 & 3,02 & 44 & 12,02 \\
\hline 28 a 34 & 24 & 6,50 & 6 & 1,60 & 30 & 8,10 \\
\hline 35 a 39 & 14 & 3,80 & 0 & - & 14 & 3,80 \\
\hline 40 a 44 & 10 & 2,74 & 10 & 2,74 & 20 & 5,48 \\
\hline 45 a 49 & 3 & 0,82 & 1 & 2,74 & 4 & 3,53 \\
\hline 50 a 54 & 6 & 1,60 & 3 & 0,82 & 9 & 2,42 \\
\hline
\end{tabular}


Tabela 3: Obituário da população de Porto Alegre por varíola segundo a faixa etária, epidemia de 1874 (cont.)

\begin{tabular}{l|c|c|c|c|c|c}
\hline \multicolumn{1}{c|}{ Idades } & $\begin{array}{c}\text { Livres } \\
\text { (n. absolutos) }\end{array}$ & $\mathbf{( \% )}$ & $\begin{array}{c}\text { Escravos } \\
\text { (n. absolutos) }\end{array}$ & (\%) & $\begin{array}{c}\text { Total } \\
\text { (n. absolutos) }\end{array}$ & Total (\%) \\
\hline $\mathbf{5 5}$ a 59 & 0 & - & 0 & - & 0 & - \\
$\mathbf{6 0}$ oumais & 4 & 1,09 & 0 & - & 4 & $1,09 \%$ \\
$\begin{array}{l}\text { Não } \\
\text { constou ou } \\
\text { ignorado }\end{array}$ & 14 & 3,80 & 0 & - & 14 & $3,80 \%$ \\
\hline
\end{tabular}

Fonte: Livro de óbitos... (1867-1874, v.11-12); CHC Santa Casa ( 2007).

Enquanto a população com mais de 40 anos apresentou alguns poucos casos de mortes por varíola, as crianças, os jovens e os adultos, até a faixa dos 30 anos, principalmente, foram duramente castigados pela epidemia. Ainda que existam diferenças significativas entre a população livre e a escrava, o número de falecimentos dos pequenos, de 0 a 5 anos, foi preponderante sobre os demais. A falta de vacinação talvez explique a alta mortalidade infantil.

Ao investigar as elaborações possíveis diante do adoecimento ou da morte em uma dada comunidade, deparamo-nos com interpretações divergentes quanto a causas, tratamentos e/ou métodos de prevenção. Obedecendo aos costumes advindos de tradições familiares ou religiosas, por exemplo, na hora de tratar seus males os indivíduos constroem seus significados de acordo com o universo de experiências compartilhadas ao longo de sucessivas gerações (Chalhoub, 1996).

A mortalidade indiscriminada de jovens, adultos e crianças na epidemia de Porto Alegre, em 1874, representa um importante indicativo para pensarmos a resistência das pessoas à vacinação, o que não quer dizer, entretanto, que os perigos da doença fossem ignorados indiscriminadamente. Sabemos que, não raro, as pessoas ditas "comuns" elaboraram seus próprios métodos de combate à doença, legitimando o conhecimento e as crenças que compartilhavam no interior de sua própria comunidade (Witter, 2007; Hochman, Armus, 2004).

Desse modo, em todo o período investigado, a mortalidade cativa por varíola foi infinitamente menor que entre os livres. Durante a epidemia, esse cenário permaneceu intacto, o que pode ser explicado pela presença cada vez menor dos escravos entre a população, tendo em conta a pressão abolicionista, que já caminhava a passos largos em meados da década de 1870 no Brasil e na província. ${ }^{22}$ Mesmo assim, na epidemia de 1874, enquanto faleceram 93 crianças livres, entre 0 e 5 anos, há ocorrência de um óbito apenas entre os escravos da mesma faixa etária.

A população escrava pode ter sido alvo de vacinação, por exemplo, o que talvez não tenha ocorrido com os livres. Tânia Fernandes afirmou que, de modo geral, a vacinação entre os escravos alcançou números expressivos. Nas palavras da autora:

Apesar da obrigatoriedade para uma fração delimitada da população, a vacinação não se fez cumprir. A única obrigatoriedade cumprida era aquela ditada pela escravidão nas fazendas, para onde o vacinador era deslocado por solicitação dos proprietários de escravos, o que alcançava cerca de $40 \%$ da vacinação em relação aos demais vacinados (Fernandes, 2010, p.47). 
Não tivemos acesso ao número de crianças vacinadas durante o período imediatamente anterior à epidemia. Mas se os escravos estiveram entre o público que mais recebera a lanceta, como defendeu Fernandes, talvez as crianças em situação de cativeiro estivessem imunizadas no momento da eclosão da epidemia, o que não ocorrera com os pequenos livres. O grupo etário com maior incidência de mortes entre os escravos foi justamente aquele em que os sujeitos se encontravam no auge de sua força física, entre os 18 e os 27 anos; um indicativo da ausência de vacinação entre esses grupos.

Os indivíduos livres, entretanto, compuseram grupo de alto risco durante a epidemia de varíola ocorrida em Porto Alegre; morreram em massa, enquanto os escravos estiveram, por algum motivo, mais protegidos daquele flagelo. Talvez um estudo mais aprofundado, que leve em conta os mapas de vacinados em outras localidades ou os costumes professados por grupos de escravos no combate à varíola à época, pudesse apontar uma saída para essa interrogação. Por ora, sigamos a análise com os instrumentos de que dispomos.

Um último dado que pretendemos analisar quanto ao perfil mais geral da população que faleceu por varíola em 1874 é justamente o sexo daqueles indivíduos. Observando a Tabela 4, vemos que não houve proporção no que se refere aos óbitos de homens e mulheres livres. O mesmo caso foi verificado entre a população escrava.

Tabela 4: Obituário da população de Porto Alegre por varíola segundo o sexo, epidemia de 1874

\begin{tabular}{c|c|c|c|c}
\hline Sexo & $\begin{array}{c}\text { Livres } \\
\text { (n. absolutos) }\end{array}$ & $\begin{array}{c}\text { Livres } \\
(\%)\end{array}$ & $\begin{array}{c}\text { Escravos } \\
\text { (n. absolutos) }\end{array}$ & $\begin{array}{c}\text { Escravos } \\
\text { (\%) }\end{array}$ \\
\hline Masculino & 181 & 57,4 & 30 & 61,2 \\
$\begin{array}{c}\text { Feminino } \\
\text { Não constou } \\
\text { (indefinido) } \\
\text { Total }\end{array}$ & 126 & 40 & 17 & 34,6 \\
\hline
\end{tabular}

Fonte: Livro de óbitos... (1867-1874, v.11-12); CHC Santa Casa (2007).

Isolando apenas o sexo dos sujeitos, constatamos que a população masculina apresentou maior percentual de óbitos entre livres e escravos. Os varões estiveram mais vulneráveis ao contágio, e talvez a atividade da guerra possa explicar essa questão. Muitos deles, segundo consta em seu registro de óbito, eram soldados do $12^{\circ}$ Batalhão de Infantaria, outros, músicos do mesmo batalhão. Pelo menos 13\% dos homens livres que morreram durante a epidemia exerciam atividades no Exército (Livro de matrícula..., 1874, s.p.).

Sob esse aspecto, cabe ressaltar que os primeiros óbitos registrados durante a epidemia são exatamente os de cinco soldados, sendo que quatro deles eram oriundos de outras províncias. Manoel, Anselmo, Raimundo, João Paulo e Pedro Bento foram enterrados em datas próximas no cemitério do Campo Santo, e, ao lado de seus nomes, havia a seguinte observação: soldado do $12^{\circ}$ Batalhão de Infantaria. Dos cinco homens, apenas Pedro Bento era originário da província. Após sua morte, em fevereiro de 1874, seguiu-se o falecimento de mais 359 pessoas. Essa elevada mortalidade expõe a facilidade com que a doença se espalhou naquele período ao longo do vasto território do Império do Brasil, além da 
fragilidade de ação dos agentes encarregados pela vacinação praticada há mais de 20 anos na província de São Pedro.

No início de 1874, as notícias sobre a salubridade pública, em geral, não eram boas em muitas províncias do Brasil. A moléstia das bexigas estava espalhada por diversas localidades, e os relatórios de presidentes da província anunciavam, naquele ano, numerosas baixas em função da doença. Encontramos relatos da manifestação da varíola em formato epidêmico em pelo menos dez províncias, incluindo a de São Pedro do Rio Grande. Esses preciosos relatórios expunham as características de atuação das autoridades da época, no que se referia ao trato com a doença e os doentes. Alguns deles são ricos em detalhes, informando-nos, também, as reações da população quanto a epidemia e a vacina, que poderiam ser muito diversificadas (Relatório de João..., 1874, s.p.).

Em 1873 e 1874, a epidemia de varíola grassou novamente em várias localidades do Império, como Minas Gerais, Pará, Maranhão, São Paulo, Rio de Janeiro e Paraná. Segundo Eugênio (2004), somente em Minas Gerais, a varíola teria atacado 29 municípios da província. A situação em Minas Gerais fora tão grave que nem mesmo médicos e vacinadores se dispunham a trabalhar em prol da humanidade enferma no auge da epidemia, pois, se não havia consenso com respeito ao fator que gerava a doença, sabia-se bem, devido aos anos de experiências acumuladas no trato de moléstias como a varíola, que o contágio se dava com muita facilidade entre pessoas que compartilhavam o mesmo ambiente.

Assim, em lugares onde havia aglomeração de pessoas, a propagação da varíola ocorria rapidamente. Para Eugênio (2004, p.233), os pobres e desvalidos foram os mais atingidos pela epidemia em Minas Gerais, tendo forçado as autoridades a tomar atitudes que impedissem a propagação da doença para os membros mais abastados da sociedade, "pois as tragédias deles poderiam se espalhar para toda a sociedade".

Esse mesmo cenário foi observado por Cristina Sotto (1992) em Taubaté, cidade paulista que, segundo a autora, contabilizou 423 mortos por varíola em apenas três meses de 1874 . Para Sotto, o problema da epidemia era tão grande que, pela primeira vez após anos de esquecimento, a doença voltou com intensidade à pauta dos vereadores da cidade, que organizaram medidas profiláticas para combatê-la, como a vacinação e o isolamento em lazaretos. Tais medidas, elaboradas às pressas, no entanto, não lograram o êxito almejado - pois se destinavam a controlar uma parte da população, pobre e negra preferencialmente, enquanto a doença atingia praticamente todos os setores sociais.

A cidade de Iguassu, no Paraná, também teria sofrido com o contágio da moléstia naquele ano. Segundo Dalledone (1980, p.212), a varíola, que era endêmica na região, manifestou-se em seu formato epidêmico, tendo provocado muitas mortes, o que garantiu a mobilização das autoridades para extinguir aquele mal: "Para atender a população foi nomeada uma comissão sanitária, autorizada pelo governo a despender a verba de 1:000\$000rs com o tratamento dos variolosos". Outras cidades, como Curitiba, Lapa e o porto de Antonina, teriam sofrido com a moléstia, conforme relatório do vice-presidente da província, que classificou o contágio por varíola "como uma verdadeira tragédia dos pobres e desvalidos. Um mal que não poderia ser combatido enquanto reinasse a ignorância, ao invés da vacina e das boas medidas higiênicas" (Relatório de Frederico... 1874, s.p.). 
Como pudemos observar, a varíola esteve presente em muitas localidades do Império entre 1873 e 1874. Em algumas cidades, como Belém do Pará, por exemplo, o surto epidêmico se deu em 1873, pois em relatório, no ano seguinte, o presidente já informava estar controlado o surto das bexigas naquele território. Já em Porto Alegre, cidade que investigamos com mais detalhamento, a varíola teria realizado mais estragos a partir de maio de 1874, embora os primeiros óbitos relacionados à epidemia tenham ocorrido em fevereiro daquele ano.

Ao verificar a origem e a condição militar dos primeiros homens que faleceram por varíola em Porto Alegre, nos deparamos com um problema aparentemente difícil de resolver. Como vimos, em 1865 as bexigas causaram sérios estragos entre os sujeitos envolvidos na Guerra do Paraguai; muitos soldados, cabos e mesmo tenentes ou alferes foram enterrados na capital sulina, vítimas da doença. A população da cidade, entretanto, esteve relativamente protegida, tendo apresentado alguns poucos óbitos. Mas, em 1874, isso não se repetiu. Mesmo que existam semelhanças com o cenário de 1865, haja vista a posição militar dos agentes que supostamente contribuíram para a disseminação da doença, as razões que expuseram o restante da população ao contágio em 1874 devem ser buscadas na história de outro conflito, dessa vez, no interior da província.

Os soldados do $12^{\circ}$ Batalhão de Infantaria Manoel, Joaquim, Raimundo e João Paulo não estiveram em Porto Alegre naquele momento por acaso. Sua passagem pela capital deve estar intimamente ligada ao conflito do Ferrabrás, conhecido como revolta dos Muckers. ${ }^{23} \mathrm{O}$ batalhão ao qual pertenciam fora destacado para lutar contra os colonos em 1874. Segundo Janaína Amado (2002, p.283; destaque nosso),

A 27 de junho, o presidente da província viajou até São Leopoldo para entender-se com o chefe da polícia. A partir daí começaram a chegar armas, munição e soldados, vindos por terra, pelo rio dos Sinos em lanchões, ou por trem, na recém-inaugurada estrada de ferro para São Leopoldo. Foram enviados cerca de 92 praças do ' $12^{\circ}$ Batalhão de Infantaria', 40 praças da Guarda Nacional de Porto Alegre, armas, munição e dinheiro.

Ao longo de 1874, 14 soldados do dito batalhão foram enterrados no cemitério do Campo Santo; alguns deles, como Albino Francisco Torres, natural do Rio de Janeiro, ou Manuel Evangelista, do Maranhão, faleceram por varíola em datas próximas ao primeiro combate no Ferrabrás, para o qual, segundo Amado, seu batalhão fora designado. Evangelista teria passado, ainda, pelo lazareto dos Moinhos de Vento no auge da epidemia, onde conviveu com escravos da cidade e homens pobres como ele, antes da morte. ${ }^{24}$

A diferença fundamental entre a Guerra do Paraguai em 1865 e aquela travada contra os colonos do Ferrabrás em 1874 esteve no contato dos soldados do dito batalhão de infantaria com a população em geral. Uma vez doentes de varíola, esses homens, circulando por via terrestre, seriam vetores da doença, transmitindo-a para os habitantes da cidade de Porto Alegre, de onde provavelmente saíam. ${ }^{25}$

Culpar esses soldados pelo falecimento de $1 \%$ da população da cidade seria, entretanto, um equívoco histórico. Talvez esses homens tenham contribuído para agravar, naquele ano, um quadro nosológico que já existia há séculos na província de São Pedro. O fato de pertencerem a outras províncias, entre as quais Pará e Maranhão, que também sofreram 
pela manifestação da varíola em 1873, demonstra que a circulação de pessoas entre as diferentes localidades do Império era fator preponderante na disseminação da moléstia, além de expor as fragilidades do Estado imperial no que dizia respeito ao controle de epidemias.

Mesmo que as condições para a disseminação da varíola estivessem presentes na capital da província, no ano anterior à manifestação epidêmica não encontramos nenhum óbito pela doença em Porto Alegre nem qualquer relato de contágio na documentação da Santa Casa de Misericórdia de Porto Alegre - o que nos leva a acreditar que a varíola estivesse controlada na cidade até 1873, quando, provavelmente, indivíduos contaminados, chegados de outras localidades, contribuíram para a emergência de um novo foco epidêmico na cidade.

Assim como as crianças, homens e mulheres muito jovens também perderam a vida em função das bexigas. Teriam sido vacinados? Acreditamos que não. Em uma situação de controle da doença, as pessoas não estiveram dispostas a inocular em seus corpos o pus vacínico, pois havia receio e desconfiança daquele método, professado por alguns poucos homens, que não necessariamente mantinham diálogo com a população, no sentido de esclarecer a importância da profilaxia.

O incipiente Estado imperial brasileiro não fora capaz de coordenar as medidas que seus agentes responsáveis pela saúde propunham, e a população da cidade de Porto Alegre enfrentou a varíola durante todo o século XIX. Em alguns períodos, a doença esteve controlada, mas esse controle não era regra. Dessa maneira, o exame dos embates em torno da varíola e do perfil social dos variolosos, atores que vivenciaram a experiência da doença no século XIX, levou-nos a concluir que a vacinação não atingiu um público expressivo em Porto Alegre.

A chegada de soldados portando varíola e sua posterior circulação pela capital sulina certamente contribuíram para que a doença se manifestasse epidemicamente. $\mathrm{O}$ baixo índice de vacinados e, sobretudo, a resistência dos diferentes sujeitos em aderir ao preventivo garantiram, contudo, as condições para que a doença ganhasse força entre a população da cidade. Finalmente, a experiência da saúde e do adoecimento de muitos homens e mulheres acometidos pela varíola no século XIX mostrou-se reveladora da ação social, dos padrões de comportamento considerados legítimos na hora de tratar ou prevenir seus males e dos recursos disponíveis e praticados naquela sociedade, por aqueles sujeitos, em relação aos desastres de uma epidemia.

\section{NOTAS}

${ }^{1}$ Dados sobre os sujeitos citados podem ser encontrados em Livro de matrícula... (1874).

${ }^{2}$ O período de tempo investigado compreende os anos de 1846 a 1874, entre a introdução da vacinação contra a varíola na província e a eclosão da epidemia em Porto Alegre (Brizola, 2014).

${ }^{3}$ Antes de 1850, os enterramentos eram responsabilidade da Cúria de Porto Alegre. Os documentos correspondentes a esses quatro anos foram analisados em separado, com o intuito de abranger o marco temporal da pesquisa. Contudo, a maior parte das conclusões aqui apresentadas foram pensadas a partir de fontes do Centro de Documentação e Pesquisa da Santa Casa de Misericórdia de Porto Alegre.

${ }^{4}$ Para Castro (1999), mais do que uma corrente historiográfica, a história social desde sua primeira abordagem constituída sob influência dos Annales na França, na década de 1930, parte da preocupação de historiadores como Marc Bloch, Lucian Fevbre e, mais tarde, Fernand Braudel em se opor a uma visão factualista da 
história, centrada nas decisões e ideias de grandes homens ou nos acontecimentos protagonizados por eles (Batalha, 1988).

${ }^{5}$ Estabelecendo uma definição para a identificação da doença, Chernoviz (1890) alerta que a varíola, ou bexigas simples, constitui-se enquanto erupção geral de borbulhas pelo corpo que se convertem em grandes pústulas redondas e purulentas, acabam pela dessecação e deixam nódoas vermelhas, às quais sucedem cicatrizes mais ou menos aparentes.

${ }^{6}$ Segundo Gazeta (2006), o cálculo dos óbitos por varíola em relação aos contágios só pôde ser mais bem avaliado a partir do século XX, quando verificamos um controle mais rígido desses números, proporcionado por campanhas de erradicação da doença.

${ }^{7}$ Para uma apreciação detalhada acerca dos impactos gerados pelo cólera na província de São Pedro em meados do século XIX, ver Witter (2007).

${ }^{8}$ Essa estimativa pode ser visualizada no trabalho de Rego (1851).

${ }^{9}$ Para Rodrigues (1999), o elevado número de óbitos ocorridos naquele ano foi elemento catalizador das mudanças de ordem funerária. Médicos e higienistas viam com maus olhos os enterramentos praticados dentro dos templos ou mesmo no interior da urbe. Ver também Chalhoub (1993).

${ }^{10}$ A técnica da variolização, segundo Fernandes (2010), consistia na inoculação do pus variólico, retirado de pústulas de sujeitos portadores de varíola, em pessoas que não haviam adquirido a doença. A medida seguia um princípio similar ao usado por Jenner, no final do século XVIII, que observou que as mulheres que ordenhavam vacas com cowpox, o vírus que acomete os bovinos, similar ao smallpox humano, ficavam imunes à doença. Daí a hipótese vacinal (Darmon, 1999; Moulin, 2003).

${ }^{11}$ A lei de 1846 recomendava que os vacinados comparecessem no prazo de oito dias ao instituto onde receberam o preventivo para a retirada do pus que serviria para inocular outros indivíduos (Fernandes, 2010). Chalhoub constatou a mesma resistência da população carioca em retornar ao Instituto Vacínico após o período de uma semana. Para o autor, as pessoas "resistiam a esse retorno demorado e incômodo, o que provocava uma constante queda de braço entre a população e os vacinadores, os últimos frequentemente apoiados na autoridade policial" (Chalhoub, 1996, p.113-114).

12 Os anos mencionados no quadro estatístico da população livre e escrava, investigado por Moreira, são próximos aos anos para os quais encontramos mapas de vacinados. Assim, para 1856, por exemplo, utilizaremos os dados de vacinação de que dispomos do ano anterior, julho de 1854 a julho de 1855 . Para 1860, comparamos com os dados de vacinados de 1861 e 1862. Por fim, os números encontrados para 1871 serão comparados com os dados populacionais apresentados por Moreira (2003) para 1872.

${ }^{13}$ Para uma crítica bem formulada acerca dos problemas na transposição dos conceitos foucaultianos para pensarmos a realidade da saúde e da medicina no Brasil do século XIX, ver Antunes (1999), Telarolli Jr. (1996) e Edler (2011).

${ }^{14}$ As diferenças de entendimentos entre as concepções de médicos e práticos quanto à funcionalidade da vacina ou as formas de combater doenças diversas foram uma constante no período. Ver o caso dos embates jurídicos levados a cabo por dois médicos importantes da capital da província no século XIX, o vacinador doutor Roberto Landell e o presidente da Comissão de Higiene, doutor Ubatuba, estudado por Brizola (2014, p.64).

${ }^{15}$ Moulin $(1996,2003)$ destacou a grande influência exercida pelas descobertas de Jenner nas ações estatais no século XIX em diversas partes do mundo. Durante o século XIX, principalmente a partir de sua metade, as experiências de Jenner foram sendo aprofundadas e a elas se incorporaram as investigações que marcaram a ciência biomédica do período, notabilizada pelo aprimoramento do método experimental.

${ }^{16}$ Relatos obtidos a partir da documentação da Câmara Municipal de Porto Alegre acerca da aplicação da vacina no período estudado nos informam a negligência da população em aderir ao preventivo, e sua resistência em vacinar as crianças recém-nascidas (Atas..., 1874), fato observado também por Chalhoub (1996) em seu estudo sobre a vacina na Corte.

${ }_{17}$ Sobre a história de Porto Alegre no século XIX, em uma perspectiva ampliada, ver Spalding (1967), Pesavento (1990) e Mauch (2004).

${ }^{18}$ Nesses anos, os números absolutos de óbitos foram: 114 em 1854; 86 em 1863 e 253 em 1865, entre a população livre e escrava.

${ }^{19}$ A arregimentação e mobilização dos contingentes militares estão diretamente relacionados à invasão paraguaia do território do Rio Grande do Sul, entre junho e agosto de 1865. Para mais detalhes, ver Doratioto (2002). 
${ }^{20}$ Dados sobre os soldados que foram a óbito por varíola em 1865 podem ser visualizados em Livros de óbitos... (1856-1866).

${ }^{21}$ Note-se que $49 \%$ dos homens que faleceram naquela ocasião compunham o corpo do Batalhão de Voluntários da Pátria; 8,7\% pertenciam ao Pelotão da Guarda Nacional de Porto Alegre. Com menor índice de falecimentos, aparece o $22^{\circ}$ Batalhão de Infantaria, com $2 \%$. Os demais óbitos de militares estão distribuídos em outros contingentes que não somaram juntos 1\% dos casos (Livro de óbitos..., 1856-1866).

22 Sobre o movimento abolicionista na Província de São Pedro, ver Moreira (2003).

${ }^{23}$ Esse conflito entre colonos e as forças imperiais ficou conhecido como a guerra dos Muckers (1873-1874), tendo ocorrido na região do morro Ferrabrás, atualmente município de Sapiranga. Os Muckers acreditavamse os "escolhidos", os eleitos que salvariam os colonos de um mundo corrompido. Seu discurso começou a intimidar os setores dominantes da comunidade germânica local, que pediram auxílio ao governo provincial. Em pouco mais de um mês aconteceu a "guerra", que começou com o ataque dos colonos rebelados às regiões vizinhas do morro Ferrabrás e terminou em um massacre dos seguidores da líder religiosa Jacobina Maurer pelo Exército imperial. Para mais detalhes, ver Amado (2002).

${ }^{24}$ Entre a população sepultada no cemitério do Campo Santo, encontramos um número razoável de indivíduos que passaram anteriormente pelo lazareto dos Moinhos de Vento. A criação do lazareto esteve ligada tanto à necessidade de isolar uma parcela da população, majoritariamente escravos e pobres, quanto à falta de estrutura adequada em um momento de epidemia (Brizola, 2014, p.138).

${ }^{25}$ A referência ao termo "vetores" deve ser entendida em seu contexto geral, a ideia de reproduzir o vírus em razão de movimentação de pessoas. Inúmeros autores destacam a alta transmissibilidade da varíola, através da respiração, entre outras formas de contato (Crosby, 2011), levando a óbito 1/3 dos infectados (Gazeta, 2006).

\section{REFERÊNCIAS}

AMADO, Janaína.

A revolta dos Muckers. Porto Alegre: Unisinos. 2002 .

ANTUNES, José Leopoldo Ferreira. Medicina, leis e moral: pensamento médico e comportamento no Brasil, 1870-1930. São Paulo: Fundação Editora da Unesp. 1999.

ÁVILA, Vladimir Ferreira de.

Saberes históricos e práticas cotidianas sobre o saneamento: desdobramentos na Porto Alegre do século XIX, 1850-1900. Dissertação (Mestrado em História) - Pontifícia Universidade Católica do Rio Grande do Sul, Porto Alegre. 2010.

ATAS...

Atas da Câmara Municipal de Porto Alegre. Livro 5 (Arquivo Histórico Moysés Vellinho, Porto Alegre). 1874.

BARROS, José D'Assunção.

História serial e história quantitativa no movimento dos Annales. História Revista, v.17, n.1, p.203-222. 2012.

BATALHA, Claudio.

A história social em questão. História: Questões e Debates, v.9, n.17, p.229-241. 1988.

BRIZOLA, Jaqueline Hasan.

A terrível moléstia: vacina, epidemia, instituições e sujeitos: a história da varíola em Porto Alegre no século XIX, 1846-1874. Dissertação
(Mestrado em História) - Universidade Federal do Rio Grande do Sul, Porto Alegre. 2014.

CASTRO, Hebe.

História social. In: Cardoso, Ciro F.; Vainfas, Ronaldo (Org.). Domínios da história: ensaios de teoria e metodologia. Rio de Janeiro: Campus. 1999.

\section{CHC SANTA CASA.}

Centro Histórico-Cultural da Santa Casa. Africanos na Santa Casa de Porto Alegre: óbitos dos escravos sepultados no cemitério da Santa Casa. Porto Alegre: EST. 2007.

CHALHOUB, Sidney.

Cidade febril: cortiços e epidemias na corte imperial. São Paulo: Companhia das Letras. 1996.

CHALHOUB, Sidney.

The politics of disease control: yellow fever and race in nineteenth century Rio de Janeiro. Journal of Latin American Studies, v.25, n.3, p.441463. 1993.

CHERNOVIZ, Pedro Luiz Napoleão.

Dicionário de medicina popular e das ciências acessórias. Paris: A. Roger e F. Chernoviz. 1890.

CROSBY, Alfred.

Imperialismo ecológico: a expansão biológica da Europa. São Paulo: Companhia das Letras. 2011. 
DALLEDONE, Márcia T. Andreatta.

Condições sanitárias e as epidemias de varíola na província do Paraná, 1853-1889. Dissertação (Mestrado em História do Brasil) - Universidade Federal do Paraná, Curitiba. 1980.

DARMON, Pierre.

L'Homme et les microbes. Paris: Fayard. 1999.

DORATIOTO, Francisco.

Maldita guerra: nova história da Guerra do Paraguai. São Paulo: Companhia das Letras. 2002.

DOURADO, Maria Teresa Garritano. Doentes e famintos: cotidiano de um soldado na Guerra do Paraguai, 1864-1870. Simpósio Nacional de História, 26., 2011, São Paulo. Anais... São Paulo: Anpuh-SP. 2011. Disponível em: <http://www.snh2011.anpuh.org/resources/ anais/14/1300640084_ARQUIVO_SP2011.pdf >. Acesso em: 13 dez. 2018. 2011.

EDLER, Flávio Coelho.

A medicina no Brasil imperial: clima, parasitas e patologia tropical. Rio de Janeiro: Editora Fiocruz. 2011.

EUGÊNIO, Alison.

Fragilidade pública em face das epidemias na segunda metade do século XIX mineiro. Varia História, n.32, p.211-234. 2004.

FERNANDES, Tânia.

Vacina antivariólica: ciência, técnica e o poder dos homens, 1808-1920. Rio de Janeiro: Editora Fiocruz. 2010.

\section{FERNANDES, Tânia.}

Imunização antivariólica no século XIX no Brasil: inoculação, variolização, vacina e revacinação. História, Ciências, Saúde Manguinhos, v.10, supl.2, p.461-474. 2003.

FOUCAULT, Michel.

Microfísica do poder. Rio de Janeiro: Graal. 1996.

GAZETA, Arlene.

Uma contribuição à história do combate à varíola no Brasil: do controle à erradicação. Tese (Doutorado em História das Ciências e da Saúde) - Fundação Oswaldo Cruz, Rio de Janeiro. 2006.

HOCHMAN, Gilberto; ARMUS, Diego (Ed.). Cuidar, controlar, curar: ensaios históricos sobre a saúde e a doença na América Latina e Caribe. Rio de Janeiro: Editora Fiocruz. 2004.

LIVRO DE MATRÍCULA...

Livro de matrícula geral de enfermos. Livro 4 . (Centro de Documentação e Pesquisa da Irmandade da Santa Casa de Misericórdia, Porto Alegre). 1874.
LIVRO DE ÓBITOS DE ESCRAVOS...

Livro de óbitos de escravos de Porto Alegre, v.10. (Arquivo Histórico da Cúria Metropolitana, Porto Alegre). 1846-1850.

LIVRO DE ÓBITOS...

Livro de óbitos de livres. v.10 a 12. (Centro de Documentação e Pesquisa da Irmandade da Santa Casa de Misericórdia, Porto Alegre). 18671874.

LIVRO DE ÓBITOS...

Livro de óbitos de livres. v.5 a 9. (Centro de Documentação e Pesquisa da Irmandade da Santa Casa de Misericórdia de Porto Alegre). 1856-1866.

LIVRO DE ÓBITOS...

Livro de óbitos de livres. v.1 a 4. (Centro de Documentação e Pesquisa da Irmandade da Santa Casa de Misericórdia de Porto Alegre). 1850-1855.

MACHADO, Roberto.

Danação da norma: medicina social e constituição da psiquiatria no Brasil. Rio de Janeiro: Graal. 1979.

MAUCH, Cláudia.

Ordem pública e moralidade: imprensa e policiamento urbano em Porto Alegre na década de 1880. Santa Cruz do Sul: Edunisc; Anpuh-RS. 2004.

MOREIRA, Paulo Roberto Staudt.

Os cativos e os homens de bem: experiências negras no espaço urbano, Porto Alegre, 18581888. Porto Alegre: EST. 2003.

MOULIN, Anne-Marie.

A hipótese vacinal: por uma abordagem crítica e antropológica de um fenômeno histórico. História, Ciências, Saúde-Manguinhos, n.10, supl.2, p.499-517. 2003.

MOULIN, Anne-Marie.

L'aventure de la vaccination. Lyon: Fayard. 1996.

OLIVEIRA, Daniel.

Morte e vida feminina: mulheres pobres, condições de saúde e medicina da mulher na Santa Casa de Misericórdia de Porto Alegre (1880-1900). Dissertação (Mestrado em História) - Universidade Federal do Rio Grande do Sul, Porto Alegre. 2012.

PESAVENTO, Sandra Jatahy.

O espetáculo da rua. Porto Alegre: Editora da UFRGS. 1990.

REGO, José Pereira.

História e descrição da febre amarela epidêmica que grassou no Rio de Janeiro em 1850. Rio de Janeiro: Tipografia de Francisco de Paula Brito. 1851. 
RELATÓRIO DE ANTONIO...

Relatório de Antonio Augusto Pereira da Cunha (Center for Research Libraries). Disponível em: $<$ http://www.crl.edu/brazil/provincial/rio_ grande_do_sul>. Acesso em: 18 fev. 2018. 1866.

RELATÓRIO DE FREDERICO...

Relatório de Frederico José Cardozo de Araújo Abranches (Center for Research Libraries). Disponível em: <http://www.crl.edu/brazil/ provincial/paraná>. Acesso em: 20 fev. 2018. 1874.

RELATÓRIO DE JOÃO...

Relatório de João Pedro Carvalho de Moraes (Center for Research Libraries). Disponível em: <http://www.crl.edu/brazil/provincial/rio grande_do_sul>. Acesso em: 28 fev. 2018. 1874.

\section{RELATÓRIO DE MANOEL...}

Relatório de Manoel Antônio Galvão (Center for Research Libraries). Disponível em: $<\mathrm{http} / / /$ brazil.crl.edu/bsd/bsd/875/000007.html>. Acesso em: 28 fev. 2018. 1847.

\section{RELATÓRIOS...}

Relatórios de presidentes da província. Fundo Governantes, A7.11 (Arquivo Histórico do Rio Grande do Sul, Porto Alegre). 1871.

RELATÓRIOS...

Relatórios de presidentes da província. Fundo Governantes, A7.05 (Arquivo Histórico do Rio Grande do Sul, Porto Alegre). 1856.

RODRIGUES, Cláudia.

A cidade e a morte: a febre amarela e seu impacto sobre os costumes fúnebres no Rio de Janeiro, 1849-1850. História, Ciência, Saúde Manguinhos, v.6, n.1, p.53-58. 1999.

ROSENBERG, Charles. Introduction. Framing disease: illness, society and history. In: Rosenberg, Charles; Golden, Janet (Ed.). Framing disease: studies in cultural history. New Brunswick: Rutgers University Press. p.13-26. 1992.
SÁ, Magali Romero.

A "peste branca" nos navios negreiros: epidemias de varíola na Amazônia colonial e os primeiros esforços de imunização. Revista Latino-americana de Psicopatologia Fundamental, v.11, n.4, supl., p.818-826. 2008.

SOTTO, Cristina.

Efeitos de uma epidemia de varíola em Taubaté. Revista de História, n.127-128, p.9-35. 1992.

SPALDING, Walter.

Pequena história de Porto Alegre. Porto Alegre: Sulina. 1967.

TELAROLLI JR., Rodolfo.

Poder e saúde: as epidemias e a formação dos serviços de saúde em São Paulo. São Paulo: Unesp. 1996.

THOMPSON, Edward Palmer.

Costumes em comum: estudos sobre a cultura popular tradicional. São Paulo: Companhia das Letras. 1998.

TOMASCHEWSKI, Cláudia.

Entre o Estado, o mercado e a dádiva: a

distribuição da assistência a partir das irmandades da Santa Casa de Misericórdia nas cidades de Pelotas e Porto Alegre, Brasil, c.1847 c.1891. Tese (Doutorado em História) - Pontifícia Universidade Católica do Rio Grande do Sul, Porto Alegre. 2014.

WEBER, Beatriz.

As artes de curar: medicina, religião, magia e positivismo na República Rio-grandense, 18891928. Bauru: Edusc. 1992.

WITTER, Nikelen Acosta.

Males e epidemias: sofredores, governantes e curadores no Sul do Brasil (Rio Grande do Sul - século XIX). Tese (Doutorado em História) Universidade Federal Fluminense, Niterói. 2007. 